\title{
Circadian rhythms and new options for novel anticancer therapies
}

\author{
This article was published in the following Dove Press journal: \\ ChronoPhysiology and Therapy \\ 5 January 2015 \\ Number of times this article has been viewed
}

\section{Ursula Prosenc Zmrzljak \\ Faculty of Medicine, Center for Functional Genomics and Bio-Chips, Institute of Biochemistry, University of Ljubljana, Ljubljana, Slovenia}

\begin{abstract}
The patterns of activity/sleep, eating/fasting, etc show that our lives are under the control of an internal clock. Cancer is a systemic disease that affects sleep, feeding, and metabolism. All these processes are regulated by the circadian clock on the one hand, but on the other hand, they can serve as signals to tighten up the patient's circadian clock by robust daily routine. Usually, anticancer treatments take place in hospitals, where the patient's daily rest/activity pattern is changed. However, it has been shown that oncology patients with a disturbed circadian clock have poorer survival outcomes. The administration of different anticancer therapies can disturb the circadian cycle, but many cases show that circadian rhythms in tumors are deregulated per se. This fact can be used to plan anticancer therapies in such a manner that they will be most effective in antitumor action, but least toxic for the surrounding healthy tissue. Metabolic processes are highly regulated to prevent waste of energy and to ensure sufficient detoxification; as a consequence, xenobiotic metabolism is under tight circadian control. This gives the rationale for planning the administration of anticancer therapies in a chronomodulated manner. We review some of the potentially useful clinical praxes of anticancer therapies and discuss different possible approaches to be used in drug development and design in the future.
\end{abstract}

Keywords: circadian rhythms, cancer, chronotherapy, detoxification metabolism

\section{Introduction}

The patterns of activity/sleep, eating/fasting, etc show that our lives are under the control of an internal clock. The major quality of the circadian clock is its maintenance in constant darkness (free-running conditions), while light at dawn serves as a resetting signal to set our clocks to approximately 24 hours. ${ }^{1,2}$ This clock is in the hypothalamus of the brain in the suprachiasmatic nucleus ( $\mathrm{SCN})$, a region above the optical chiasm (reviewed by Okamura ${ }^{3}$ and Weaver $^{4}$ ). The SCN receives photic signals from ganglion cells in the retina, which enables the SCN to sense the start of each day at dawn. The clock in the SCN is the central oscillator, but many other tissues have their own clocks as well - peripheral oscillators that regulate different tissuespecific metabolic processes. These metabolic processes have to be tightly regulated to prevent waste of energy and to ensure sufficient detoxification. Circadian clocks are maintained with finely regulated molecular mechanisms ticking in each individual cell, different cells in a tissue need to be orchestrated, and clocks between different tissues need to be synchronized. Only in that way can an organism be fully functional. If desynchronization of any of these systems occurs, or if the circadian clock stops ticking because of mutations in clock genes, then different discordances can occur that lead to the development of different diseases, including cancer.
Correspondence: Ursula Prosenc Zmrzljak Faculty of Medicine, Center for Functional Genomics and Bio-Chips, Institute of Biochemistry, University of Ljubljana, Zaloška 4, SI-I000 Ljubljana, Slovenia Tel +386 I 5437592

Fax +386 I 5437588

Email ursula.prosenc@mf.uni-lj.si 


\section{Molecular mechanisms of circadian rhythms}

The clock responsible for circadian regulation in freerunning conditions is represented by a set of transcription activators and repressors. Genes encoding the core clock components are transcribed periodically. They are involved in transcriptional-translational-post-translational modification loops that serve autoregulation as well as the regulation of circadian expression of output genes. The first core clock gene identified was Circadian locomotor output cycles kaput (Clock) ${ }^{5,6}$ It is accompanied by transcription factors Brain and muscle Arnt-like protein-1 (Bmall) and Neuronal PAS domain protein 2 (Npas2) as activators, and Period (Per) 1 and 2 and Cryptochrome (Cry) 1 and 2 as repressors. On the protein level, CLOCK/BMAL1 or NPAS2/BMAL complex binds to E-box DNA elements in promoter regions of different genes, among others, and also to promoter regions of repressors Per1,2 and Cry 1,2. 5,7,8 PER heterodimerizes with the CRY, and they bind to the BMAL1/CLOCK (NPAS2) complex and attenuate its activity. As a consequence, the transcription of Per genes is stopped, completing the first autoregulatory loop. When the pool of PER and CRY proteins is diminished owing to protein degradation, PER and CRY are removed from the BMAL1/CLOCK complex, and transcription is reactivated. ${ }^{9,10}$ The degradation of PER and CRY is controlled through posttranslational mechanisms. ${ }^{11,12}$ In addition to this core clock regulation, several oscillators help to maintain the robustness and precision.

\section{Circadian regulation of cell cycle check points and DNA repair}

The circadian clock is a cell-autonomous and self-sustained oscillator with a period of about 24 hours. In growth conditions, successive divisions and progression through the cell cycle can also be considered as a periodic process. ${ }^{13}$ The cell cycle duration in mammalian cells typically lasts on the order of 1 day. ${ }^{14}$ Cell cycle states fluctuate with circadian time in different organisms: cyanobacteria, ${ }^{15}$ fungi, ${ }^{16}$ zebra fish, ${ }^{17}$ and mammalian cells. ${ }^{18,19}$ Mitotic indices are known to exhibit clock-dependent daily variations. ${ }^{18,20,21}$ This has led to a model where the circadian clock may establish temporal windows in which certain cell cycle transitions are favored or suppressed - circadian gating of the cell cycle. Study in a regenerating mouse liver showed that WEE1, which limits the kinase activity of CDK1 and prevents entry into mitosis, is controlled at the transcription level with CLOCK/ BMAL1 and shows circadian activity. So it is functioning as a clock-dependent cell cycle gate. ${ }^{22}$ In primary fibroblasts, protein NONO interacts with PER and gates S-phase to specific circadian times. ${ }^{19}$

The hallmark of cancer is disrupted control of the cell cycle. Normal cell cycle progression requires several control check points, and if these are deregulated, this could lead to cancerogenesis. ${ }^{23}$ Many anticancer drugs act through the induction of DNA damage that causes irreparable lesions and stops the replication of DNA and leads to cell senescence. This effect is known as genotoxic stress. ${ }^{24}$ Genotoxic treatments mainly target rapidly dividing cells: bone marrow, intestinal epithelium, and hair follicles, and therefore cause common side effects such as myelosuppression, mucositis, and alopecia. All these tissues harbor functional clocks, and the circadian regulation of cell cycle check points could help protect normal tissues from genotoxic stress-induced treatments. ${ }^{25,26}$

Sensing the DNA damage at the cell cycle check points is mediated by two protein kinases: ATM (ataxia telangiectasia mutated) and ATR (ATM-Rad3 related). ${ }^{27}$ ATM is activated when DNA double-strand brakes occur and phosphorylates CHK2 kinase. PER1 interacts with ATM/CHK2 complex. When Perl is downregulated, ATM-dependent phosphorylation of CHK2 is impaired. Tumor cell lines with downregulated Per 1 are therefore more resistant to anticancer drugs. ${ }^{28}$ TIM (Drosophila homolog TIMELESS) associates with core circadian proteins PER and CRY. ${ }^{29}$ Human TIM interacts with cell cycle check point proteins CHK1, ATR, and ATR small subunit ATRIP. These interactions are stimulated with hydroxyurea and UV light, which cause DNA damages. Downregulation of TIM results in ATR-dependent phosphorylation of $\mathrm{CHK} 1 .{ }^{30}$

If the damage of DNA does appear, the cell has different mechanisms to repair it. One of the mechanisms to repair single-strand DNA brakes is nucleotide excision repair (NER). CRY evolved from the family of cryptochrome/photolyases, ${ }^{31}$ and this fact suggests that CRY could be involved in DNA repair mechanisms. Indeed, plant CDP-photolyases interact with the CLOCK/BMAL complex in a similar fashion as mammalian CRYs, and they are able to compensate for $C r y$ deficiency and restore circadian oscillations in cell lines and liver. ${ }^{32}$ Mammalian CRYs regulate the NER mechanism, which displays daily oscillations in the brain and liver. ${ }^{33,34}$ NER also removes cisplatin-induced DNA damage, and this activity displays circadian oscillations in liver extracts. ${ }^{34}$ NER is constantly high in Cry-deficient mice, which suggests that circadian clock downregulates the activity of NER at certain times of the day. Development of 
skin tumors depends on time of exposure to carcinogens and negatively correlates with NER activity. ${ }^{35}$

The circadian clock mechanism is also involved in the double-strand brakes repair mechanism. When checked for genes that are involved in mitomycin $\mathrm{C}$ sensitivity, the list of candidate genes included also CLOCK protein. In experiments with laser-induced damage, CLOCK was shown to colocalize with $\gamma$-H2AX protein, marker of double-strand DNA brake sites. ${ }^{36}$ These findings define core circadian clock protein CLOCK as a regulator of several mechanisms of DNA repair induced by different genotoxic agents. ${ }^{37}$

\section{Circadian rhythms and cancer}

The circadian clock regulates the normal cell cycle and apoptosis, ${ }^{38}$ and anticancer drugs usually target different stages of the cell cycle, so differences in the cell cycle in cancerous versus healthy cells represent the rationale of anticancer chronotherapy. ${ }^{39}$ In mice and rats, rhythm in tolerance of many anticancer drugs was shown: cytokines, cytostatics, antiangiogenic agents, cell cycle inhibitors, etc. ${ }^{39}$ Experimental evidence shows that both dose and circadian timing play a critical role in antitumor efficacy, using tumor growth inhibition and increase in life span as measure. ${ }^{39}$

Alterations in clock genes in tumors versus healthy tissue can cause increased susceptibility to develop cancer and poor patient survival. This was shown for colorectal cancer, ${ }^{40,41}$ chronic lymphocytic leukemia, ${ }^{42}$ epithelial ovarian cancer, ${ }^{43}$ and breast cancer. ${ }^{44}$ In various epidemiological studies, it was shown that single nucleotide polymorphisms in clock genes are associated with higher cancer risk for prostate cancer (CRY2 rs1401417: G $>$ C, 1.7-fold higher risk), ${ }^{45}$ breast cancer (NPAS2 Ala394Thr) ${ }^{46}$ non-Hodgkin's lymphoma (CRY2 rs11038689, rs 7123390, rs1401417), ${ }^{47}$ and colorectal carcinoma (CLOCK1 311T >C, CC 2.78-fold and TC 1.78-fold higher risk). ${ }^{48}$ Gene expression of all three $P E R \mathrm{~s}$ is deregulated in breast cancer cells, and PER1 expression is downregulated in most patients. ${ }^{49}$ PER 1 is downregulated in non-small lung cancer tissues compared with matched normal tissues. ${ }^{28}$ PER2 mRNA levels are downregulated in several human lymphoma cell lines and in acute myeloid leukemia patients. ${ }^{50}$ In breast cancer, PER2 can bind to and destabilize estrogen receptor $\alpha .^{51}$ Polymorphisms in the number of tandem repeats in the polymorphic domain of PER3 can cause circadian disruption, increase inflammation by increased IL-6 levels, and therefore increase cancer risk. ${ }^{52}$ Mutations in NPAS2 are associated with increased risk for breast cancer and non-Hodgkin's lymphoma. ${ }^{47}$
Per 2 mutant mice are predisposed to oncogenic transformation following $\gamma$-radiation, ${ }^{53}$ and crossing of Per 2 mutant mice with $A p c^{\mathrm{Min} /+}$ increases the frequency of polyp formation. ${ }^{54,55}$ Downregulation of Per2 expression increases tumor growth in vivo, ${ }^{56}$ and overexpression inhibits tumor growth. ${ }^{57}$ Similar effects are also observed for Per $1 .{ }^{28,58}$ Lower levels of Perl and Per2 expression are found in human colorectal cancer tumors. ${ }^{59,60}$ All of the foregoing show that functional circadian clock might operate as a tumor suppressor. ${ }^{61}$ Further evidence that circadian clock is disrupted in cancer is shown in the study of Soták et al: ${ }^{61}$ the expression profile of $D b p$ had robust circadian rhythmicity in the colonic mucosa of healthy mice and in the surrounding nonneoplastic tissue of tumor-bearing mice, but the amplitude of the tumors was reduced, and the amplitude was delayed. The rhythmic expression of core clock genes was markedly reduced in comparison with surrounding nonneoplastic tissue, and even more in comparison with colon mucosa of healthy animals.

Animal models used for studying tumors were treated with azoxymethane (AOM), following consumption of dextrane sodium sulfate (DSS). Soták et al ${ }^{61}$ showed that circadian rhythm in AOM mice changed, the possible mechanisms being: mutations of K-ras cascade lead to activated MAPK/ERK pathway, which represses BMAL1 by phosphorylation by MAPK; mutations in $\beta$-catenin activate the Wnt signaling pathway and prevent GSK3 $\beta$ phosphorylation that can modulate $\mathrm{PER} 2^{55}$ and $\mathrm{BMAL} 1^{62}$ protein stability; mutations in the TGF $\beta$ pathway cause TGF $\beta$ to bind to its type 2 receptor, as a result of which phosphoSMAD3 forms a dimmer with SMAD4 and activates the transcription of the Dec1 gene - regulator of the clock. ${ }^{63}$ All these pathways can also be involved in the induction of tumorigenesis.

A recent article describes using the cell line systems where RAS mutations were induced and transcription was measured with microarrays according to the circadian time. Results indicate that this mutation, which is a common driver of cancers (especially colorectal cancer), deregulates the circadian clock in cancers. ${ }^{64}$ These results raise the question as to whether the deregulation and desynchronization of the circadian clock (as in shift-work) ${ }^{65}$ cause cancer or whether cancer-causing mutations alter the circadian clock in tumors, thereby causing them to desynchronize. ${ }^{64}$

\section{Epigenetic mechanisms and circadian clock}

Epigenetic mechanisms are modifications of histones and/or methylation of DNA that influence compaction of chromatin 
and accessibility of gene promoters to the transcription machinery. They are considered as mechanisms of transcription regulation. ${ }^{66}$ Genes encoding circadian clock proteins are regulated by epigenetic mechanisms, such as histone phosphorylation, acetylation, and methylation, which have been shown to follow circadian rhythm. ${ }^{67,68} \mathrm{CLOCK} /$ BMAL1-mediated activation of clock-controlled genes has been shown to be accompanied by circadian changes in histone acetylation at their promoters. ${ }^{69}$ In fact, the transcriptional factor CLOCK has also histone acetyltransferase activity. ${ }^{70} \mathrm{CLOCK}$ binds to E-box regions of DNA and can activate the transcription of clock-controlled genes. CLOCK can also acetylate nonhistone proteins: it acetylates its transcription partner BMAL1 and facilitates CRY-dependent repression. ${ }^{71}$ CLOCK associates also with histone methyltransferase MLL1 (mixed lineage leukemia 1) and recruits it to the promoters of clock-controlled genes. ${ }^{72}$ MLL1 methylates histone $\mathrm{H} 3$ at lysine 4 (H3K4). This modification at the promoters of clock-controlled genes defines the active chromatin state and is rhythmical.

Histone deacetylase SIRT1 is a modulator of circadian clock machinery. ${ }^{73}$ SIRT1 activity is $\mathrm{NAD}^{+}$dependent and is therefore metabolically regulated. ${ }^{74}$ The activity of SIRT1 is circadian and is directly driven with rhythmic oscillations in $\mathrm{NAD}^{+}$levels. ${ }^{75}$ The CLOCK/BMAL1 complex interacts with SIRT1 and recruits it to the promoters of rhythmic genes. SIRT1 also deacetylates nonhistone proteins such as BMAL1 (signal for CRY recruitment) ${ }^{71}$ and PER2 (enhances stability). ${ }^{73}$ SIRT1 also regulates several proteins involved in metabolism and cell proliferation. Gluconeogenesis is regulated via deacetylating PPAR $\gamma$-coactivator $\alpha(\mathrm{PGC} 1 \alpha)$ and Forkhead box O1 (FOXO1). ${ }^{76}$ FOXO1 directly regulates several gluconeogenic genes and $\mathrm{PGC} 1 \alpha$ coactivates glucocorticoid receptor (GR). SIRT1 also regulates Liver X receptor (LXR) that regulates cholesterol metabolism. ${ }^{76}$

Histone deacetylase 3 (HDAC3) modulates acetylation of circadian genes responsible for lipid metabolism. REV-ERB $\alpha$ is controlled by the nuclear receptor corepressor 1 (NCoR1), which recruits HDAC3 to mediate transcriptional repression of target genes, such as Bmal1. HDAC3 recruitment to the genome was recently shown to be rhythmic in liver, and the depletion of either HDAC3 or REV-ERB $\alpha$ was shown to cause fatty liver phenotype. ${ }^{77} \mathrm{HDAC} 1$ forms a complex with PER2, is recruited to the Per 1 promoter, and represses its transcription. ${ }^{78}$

Altered epigenetic marks of different genes are described in several cancers regardless of anatomic region. ${ }^{79,80}$ Some of them are considered as possible diagnostic and prognostic cancer markers. ${ }^{81}$ DNA methylation is especially interesting because of its stability and simple accessibility in routine molecular diagnostic laboratories. Several regions of DNA are being considered for DNA methylation measurements also for the purposes of cancer screening programs. ${ }^{82,83}$

Acetylation-mediated epigenetic regulation of GR activity is important in the context of circadian regulation. ${ }^{84}$ The HPA axis (hypothalamic-pituitary-adrenal) is important not just as a stressor regulating system, but also as the most likely mediator of circadian signals from the central system in the SCN to the peripheral organs. Hormones involved in the HPA axis regulate one another's secretions: corticotrophinreleasing hormone (CRH) and arginine vasopressin (AVP) stimulate the pituitary gland to secrete adrenocorticotropic hormone (ACTH), which in turn stimulates the adrenal gland to produce glucocorticoids that are secreted in a circadian manner. Secreted glucocorticoids suppress higher regulatory centers, the hypothalamic paraventricular nucleus and the pituitary gland, forming a closed negative feedback loop that resets the activated HPA axis and restores its homeostasis. ${ }^{85}$ The circulating levels of corticosteroids are circadian. In humans, cortisol zenith is reached in the early morning, and the nadir at midnight. ${ }^{85}$

Glucocorticoids function is regulated with the expression of the GR (nuclear receptor superfamily 3, group C, member $1-\mathrm{NR} 3 \mathrm{C} 1$ ). It is expressed virtually in all organs and tissues of the human body. GR is present in the cytoplasm bound to a larger protein complex; after binding glucocorticoids, it is conformationally changed and translocated to the nucleus, where it binds to a specific glucocorticoid response element (GRE), in the promoter regions of various genes. GR can act as an activator or repressor regarding the coregulators that bind to it..$^{85}$ Human GR can be acetylated, and acetylation of GR attenuates the repressive effect of GR on nuclear factor $\kappa \mathrm{B} .{ }^{86} \mathrm{CLOCK}$ acetylates GR in the nucleus, after GR binds the glucocorticoids in the cytoplasm and has translocated to the nucleus. ${ }^{87}$ The rhythm of peripheral CLOCK activity (including acetylation) is circadian, and therefore the activity of GR is circadian as well and is opposite that of maximal glucocorticoid levels in the blood ${ }^{88}$ If this finetuned system is deregulated, it may lead to functional hypercortisolism in target tissues, which could be associated with development of pathologic conditions. ${ }^{88}$ Glucocorticoids regulate the immune response, and deregulation could lead to chronic inflammation, which is a common physiological state of cancer. If the theory of cancer immunosurveillance and immunoediting is considered, a deregulated and dysfunctional immune system could speed up the escape phase 
of tumor cells that would otherwise be eliminated by the immune system. ${ }^{89}$

Recently, it was shown that histone deacetylase SIRT1 can directly regulate the expression of $B R C A 1$, the gene, if mutated, that is associated with hereditary familial breast and ovarian cancers. ${ }^{90}$ BRCA1 inactivation events (mutation, promoter methylation, or knockdown) were accompanied by decreased SIRT1 levels and increased $\mathrm{NAD}^{+}$levels, and a subsequent increase in SIRT1 activity. It is yet to be proved whether the BRCA1 mutation carriers show deregulated circadian clock in organs where BRCA1 seems to be of extreme importance (breast and ovary).

\section{Circadian regulation of drug metabolism}

For the purposes of anticancer therapy design, it is essential to know how drug metabolism is regulated, at which time points according to circadian rhythm detoxification enzymes are most effective, and when clearance of drugs will be the highest.

\section{General}

Nuclear receptors are sensors for induction of proper detoxification enzymes. They are expressed in liver, white and brown adipose tissue, and display rhythmic patterns of expression. ${ }^{91}$ From the group of nuclear receptors involved in xenobiotic metabolism, the pregnane $\mathrm{X}$ receptor (PXR), the constitutive androstane receptor (CAR), and the small heterodimer partner (SHP) are strongly oscillating in the liver..$^{91}$ The three PAR bZIP proteins DBP, TEF, and HLF are direct output mediators of the core circadian clock and are expressed in the liver where they regulate various genes involved in detoxification and drug metabolism. Triple knockout mice of PAR bZIP proteins (DBP, TEF, HLF) show a high morbidity rate and hypersensitivity to xenobiotic compounds and absence of CAR circadian expression profile..$^{92}$

Nuclear receptors upregulate the expression of xenobiotic metabolizing phase I enzymes: CYPs, alcohol dehydrogenases, aldehyde dehydrogenases (Aldhs), carboxylesterases (Cess), and paraoxonases (Pons). They have oxidase, reductase, or hydroxylase activities ${ }^{93}$ and are regulated with ALAS1 and P450 oxidoreductase (POR). All CYPs require heme as a prosthetic group, and ALAS1 is the rate-limiting enzyme in heme biosynthesis. ${ }^{94}$ The availability of heme is strongly circadian, and so is the expression of Alas 1, which is regulated by NPAS2. ${ }^{95}$ The transcription of both $A L A S 1$ and $P O R$ is decreased in PAR bZIP triple knockout mice. ${ }^{92} \mathrm{In}$ these mice, the expression pattern of phase I enzymes $(C y p 2 b$, Cyp2c, Сyp2a, and Сyp $3 a$ ) is also changed: for Сyp $3 a 4$,
Cyp2a4, and Cyp2a5, direct binding of DBP was shown. ${ }^{96,97}$ The phase II group are conjugating enzymes, and they consist of many superfamilies of enzymes: sulfotransferases (SULT), UDP-glucuronosyltransferases (UGT), NAD(P)H-quinine oxidoreductases (NQO), epoxide hydrolases (EPH), Glutathione S-transferases (GST), and N-acetyltransferases (NAT) ${ }^{98}$ Most phase II enzymes show diurnal variation in expression. Phase II conjugation of xenobiotics in liver has a circadian rhythm with more glutathione conjugation in the early light phase, glucuronidation in the late light phase, and sulfation in the early dark phase. ${ }^{93}$ In the group of phase III metabolizing genes, we find transporters that help in the uptake of xenobiotics from the blood to the liver or in the elimination of the metabolized xenobiotics, and many of them show circadian rhythmicity in expression. ${ }^{99}$ Most of these phase III enzymes were initially described as chemoresistance proteins overexpressed in cancer cell lines. It may be interesting to investigate whether these transporters display a diurnal rhythmicity in visceral cancers in vivo, as this would have strong therapeutic implications. ${ }^{100}$

\section{Circadian regulation of anticancer drugs metabolism}

Circadian timing system also regulates metabolism of most anticancer drugs. The circadian rhythm of seliciclib, docetaxel, irinotecan, mitoxantrone, and vinorelbine is probably the consequence of the circadian rhythm of Cyp $3 a .^{101,102}$ Circadian tolerability of cyclophosphamide is regulated by the rhythmic Cyp2b10 and possibly Cyp2c29. Clock-control transcription factors $D b p$, Tef, and $H l f$ regulate the expression of Cess 1 and Cess2, which account for the increased biotransformation of irinotecan to $\mathrm{SN}-38$ during the light-rest phase of mice. ${ }^{101,103}$ All enzymatic activities that generate the cytotoxic forms of 5-FU are highest during the dark-active phase in mice, when 5-FU is most toxic to healthy tissues. ${ }^{104}$ The toxicity of platinum complexes is determined by the rhythmic phase of reduced glutathione (GSH). Liver and jejunum GSH levels are ten fold higher in the second half of the night compared with midnight in mice. ${ }^{105,106}$ UGT1A catalyzes detoxification of seliciclib, irinotecan, and SN-38. The highest UGT activity is reported during the dark-active phase of rats. ${ }^{107}$ But no consistent relationship is found between blood chronopharmacokinetics and chronotolerance for irinotecan, cyclophosphamide, cisplatin, carboplatin, oxaliplatin, interferon $\beta$, or seliciclib. ${ }^{39}$ The highest elimination is observed in mice treated with carboplatin at ZT8 and with oxaliplatin at ZT16, despite both drugs being least toxic at ZT16. ${ }^{108}$ 


\section{Chronomodulating drugs and their potential in cancer treatment}

One of the attractive ideas is to use chronomodulating drugs that could reset or hold the circadian cycle on a specific time point to be able to treat patients when the treatment would be most effective or help to restore the dampened clock because of the disease itself or the application of the treatment.

Circadian oscillation in cultured cells can be induced by different agents: high serum concentration, ${ }^{109}$ dexamethasone (GR agonist), ${ }^{110}$ forskolin (activator of adenylate cyclase), ${ }^{111}$ phorbol-12-myrisate-13-acetate (PMA, activator of protein kinase C), fibroblast growth factor (FGF), epidermal growth factor (EGF), insulin, calcium ionophore calcimycin (induces apoptosis by intracellular $\left.\mathrm{Ca}^{2+}\right),{ }^{112}$ endothelin, ${ }^{113}$ glucose, ${ }^{114}$ prostaglandin E2, ${ }^{115} \mathrm{NAD}^{75,116}$, heme, ${ }^{117}$ and cAMP. ${ }^{118}$ These compounds induce rhythm through different pathways. ${ }^{119}$ Thus, many different compounds could be used to modulate the circadian clock on different points of the circadian cycle.

One of the experimental approaches is to screen different chemicals and observe their effect on the circadian cycle with the use of stably transfected Luc reporter cell lines. One of such screens revealed the drug that inhibits glycogen synthase kinase $3 \beta$ (GSK-3 $\beta$ ), which shortens the period of oscillations in U2OS cells. ${ }^{120}$ In mammals, GSK-3 $\beta$ has been previously identified as a kinase that directly phosphorylates several core clock proteins and mediates their degradation (CRY2, ${ }^{121}$ CLOCK, ${ }^{122}$ and BMAL1 ${ }^{62,123}$ ); increases nuclear translocation (PER2 ${ }^{122}$ ); or increases stabilization (REV-ERB $\left.\alpha^{124}\right)$. Another group identified a small molecule, named longdaysin, that lengthens the circadian period of different cultured cells as well as mouse SCN explants. ${ }^{125}$ Longdaysin targets several protein kinases, CK1 $\delta, \mathrm{CKI} \alpha$, and ERK2. The role of $\mathrm{CK} 1 \delta$ and ERK2 in the regulation of the circadian clock was previously known, but CKI $\alpha$ was new and it appeared that it directly phosphorylates PER1 and promotes its degradation. ${ }^{125}$ If other parameters, such as amplitude of oscillation or rhythmicity, are considered, a wide screen identified several small molecules, that caused a significant increase in the amplitude. ${ }^{126}$ That correlates with the expression of clock-output genes such as Dbp and Rev-Erb $\alpha$. Some of the newly identified small molecules mediated acute induction of Per2, followed by the phase delay, as seen in the effect of forskolin on SCN slices. ${ }^{118}$ Another screen identified a small molecule that prevents degradation of CRY and lengthens the circadian period. ${ }^{127}$ This allows studies of gluconeogenesis, since CRY negatively regulates the transcription of two ratelimiting enzymes, phosphoenolpyruvate carboxykinase 1
(Pckl) and Glucose-6-phosphatase (G6pc). ${ }^{128,129}$ Treatment with this compound repressed glucagon-mediated induction of Pckl and G6pc and production of glucose, so it could be considered a potential clock-based therapy for treatment of diabetes. ${ }^{127}$

Many core clock proteins have also clock-independent physiological functions, ${ }^{130}$ so small molecules that would modulate individual clock proteins may be considered as more specific therapeutic drug. CLOCK/BMAL1 functionality was changed during genotoxic treatment, ${ }^{102}$ so screen for modulators of its functionality was performed. ${ }^{131}$ These studies used mice with different impaired clock genes, and although all were behaviorally arrhythmic, they displayed an opposite response to toxicity induced by chemotherapeutic cyclophosphamide. Animals with a deficiency of clock activators (Clock mutant mice, Bmall KO mice) were extremely sensitive to cyclophosphamide, whereas mice with a deficiency of clock repressors (Cry double KO mice) were resistant to the treatment. This data suggests that circadian transcriptional activators could be potential targets for pharmacological modulation to protect normal tissues from damage induced by genotoxic treatments. A screen of CLOCK/BMAL1 activity modulators revealed several known regulators of circadian function ${ }^{132}$ as well as some new chemicals such as organic selenium compound L-methyl selenocysteine. ${ }^{131}$ Selenium prevents the binding of transcription repressor Tieg1 to the SP-1 binding site in Bmall promoter, upregulates Bmall transcription, increases BMAL1 protein and probably activates the CLOCK/BMAL1 complex. This effect was shown in vitro as well as in vivo with the use of a selenium-supplemented diet or by injecting it. The in vivo effect was tissue-specific, since selenium-induced BMAL1 effects were seen in the liver, but not in the SCN. This means that there was no change in the behavioral parameters. This presents huge therapeutic potential, since it does not disturb the central clock. This mechanism is mediated through BMAL1 only, since selenium failed to reproduce the effects in Bmall $\mathrm{KO}$ animals. Selenium already has two major clinical implications: tumor prevention and protection against DNA damage induced by anticancer therapy - radiation. Selenium supplementation moderates mucositis induced with fractionated doses of ionizing radiation ${ }^{133}$ as well as diarrhea in treated patients with cervical and uterine cancers. ${ }^{134}$

CLOCK/BMAL1 functionality was also studied in the Cry-deficient mouse model, where an interesting mechanism of pharmacological interest was described. It has been found that $\mathrm{Cry}$ double $\mathrm{KO}$ mice in $p 53$-null background are rendered 
more sensitive to UV-light-induced apoptosis. ${ }^{135}$ This increase was due to CLOCK/BMAL1 upregulation of $p 73$-dependent apoptosis. In the absence of $p 53$, downregulation of $C r y$ enhances the expression of $p 73$, and this correlates with increased levels of the $\mathrm{Egrl}$ (early growth response 1) gene. Egrl is a positive activator of $p 73^{136}$ and is itself directly regulated by CLOCK/BMAL1. Egrl is consistently upregulated in Cry-deficient cells owing to downregulation of BMAL1. ${ }^{137}$ EGR1 binds to the promoter of $p 73$ and is a positive regulator. Negative regulator $\mathrm{C}-\mathrm{EBP} \alpha$ is also present at the $p 73$ promoter, but upon exposure to UV light, only EGR1 stays bound to it. A similar effect was observed when tumor xenografts were treated with oxaliplatin. ${ }^{137}$ These findings suggest a therapeutically interesting mechanism for sensitizing tumor cells that are deficient in p53 function through the activation of the $p 73$-dependent apoptotic pathway.

\section{Chronotherapies in oncology: possibilities and options}

The idea of chronotherapy is to administer each drug according to a delivery pattern with precise circadian times in order to achieve the best tolerability and efficacy. ${ }^{138}$ Multichannel programmable pumps enable drug administration according to precisely timed infusion rates in order to deliver chronotherapy with minimal interference with the circadian pattern of the daily life of the patient. ${ }^{139}$ Even oral chemotherapy can be administered in optimal chronotherapy fashion. The examples of good practices of oral chronotherapy are described for busulfan, ${ }^{140} 6$-mercaptopurine, ${ }^{141}$ and oral fluoropyrimidines. ${ }^{142}$ In future, oral chemotherapeutics could be delivered with chronoprogrammed release formulation that would not disturb the patient's nighttime sleep rhythm. ${ }^{143}$

Oncological chronotherapies were extensively studied on rodents. Circadian timing largely modifies the extent of toxicity of many anticancer drugs: cytostatics, cytokines, and targeted biological agents. A lethal dose of any of these drugs results in two fold to more than ten fold changes as a function of circadian timing of drug administration. ${ }^{39}$ Such large differences occur irrespective of delivery route (oral, intravenous, intraperitoneal, or intra-arterial) or the number of daily or weekly administrations. Circadian rhythms in the tolerability of anticancer drugs persist in rodents kept in constant darkness or in constant light, which demonstrates their endogenicity. Circadian time for best tolerability and efficacy was determined for several chemotherapeutic drugs, and both times overlap. Even when combined, chemotherapeutic agents display the least toxicity near their respective times of best tolerability as single agents, as shown for doxorubicin-cisplatin in Lou rats, ${ }^{144}$ irinotecan-oxaliplatin, ${ }^{145}$ or gemcitabine-cisplatin ${ }^{146}$ in B6D2F1 mice, and docetaxel-doxorubicin in $\mathrm{C} 3 \mathrm{H} / \mathrm{He}$ mice. $^{147}$

The first clinical study that showed that therapy timing is important for the best outcome was on patients with non-small cell lung cancer. ${ }^{148}$ Trials with ovarian cancer patients showed better tolerability as compared with treatment 12 hours apart. DNA-intercalating agents doxorubicin and epirubicin were best tolerated when administered in the morning, and alkylating-like drug cisplatin when administered in the late evening. ${ }^{149,150}$ This initial finding did not alter the clinical practice for drug administration because of practical difficulties until the development of programmable intravenous systems that enable chronomodulated administration of up to four drugs. A good example is commonly used chemotherapeutic oxaliplatin that was initially found too toxic in Phase I clinical testing for use in colorectal carcinoma. Chronotherapeutic mouse studies revealed a ten fold change in toxicity with respect to dosing time. ${ }^{108}$ This finding led to the randomized Phase I two-arm study: in the first one, patients received chronomodulated infusion with peak at $4 \mathrm{pm}$ as compared with the second arm, where patients were treated with constant rate infusion. Chronotherapy induced fewer peripheral sensory neuropathies, as this is the most common side effect of the drug. ${ }^{151}$ A study on metastatic colorectal cancer patients showed that most antitumor activities were recorded in the group of patients on chronotherapy. ${ }^{152}$

Chronomodulated oxaliplatin infusion was combined with 5-fluorouracil-leucovorin (5-FU-LV) with a peak flow rate at $4 \mathrm{am}$. On the incidence of mucosal toxicities and the peripheral sensory neuropathy, the researchers concluded better tolerance as compared with constant rate infusion. ${ }^{153,154}$ The best tolerated chronotherapy schedule also achieved best tumor shrinkage. ${ }^{24}$ When compared with the conventional delivery schedule of the same drugs, overall survival was similar in both treatment groups. ${ }^{155}$ Chronomodulated drug delivery significantly reduced the risk of early death in male patients by $25 \%$, while the opposite finding was recorded for female patients. Median survival showed a difference of 6 months between men and women on the chronomodulated drug delivery regime, while no sex-related difference in survival was found in patients on a conventional delivery regime. The majority of preclinical studies were performed on male mice, and findings adequately predict the optimal timing for male patients, since the researchers did not have any valid prediction for female patients. It has been shown that sex difference is important in chronotolerance of irinotecan in 
mice. ${ }^{156,157}$ The rhythmic expression of almost 2,000 genes when compared in the oral mucosa of healthy male and female volunteers differed. In this group, we can also find clock-controlled genes important for drug metabolism and cellular proliferation. ${ }^{20}$ In general, drug metabolism pathways indeed display sex differences. ${ }^{158}$ Cry 1 and Cry 2 seem to be important to sustain sex-related differences in drug metabolizing cytochrome $\mathrm{P} 450$ dimorphism. ${ }^{159}$

In the conventional delivery protocol, the higher the toxicity is, the more efficient is the chemotherapy, but in the chronomodulated delivery protocol, the higher the toxicity, the poorer the outcome predicted. Toxicity was measured with the rate of severe neutropenia. ${ }^{160}$ The European clinical trial confirmed that chronomodulated therapy of hepatic metastasis of colorectal cancer with irinotecan, 5-FU, and oxaliplatin administered through hepatic arterial infusion was safe and that one-third of patients manifested tumor shrinkage. ${ }^{161}$ Design of the time schedule proved to be important also for radiation therapy in patients with head and neck cancer, where morning procedures caused less severe oral mucositis as compared with afternoon procedures. ${ }^{162}$ Similarly, the morning gamma knife radiosurgery doubled median survival as compared with the afternoon procedure. ${ }^{163}$

Another approach for anticancer treatment is immunotherapy, where therapies are focused on the adaptive immune response system: on cytotoxic $\mathrm{T}$ cell response and, more recently, stimulation of CD4+ T helper cells (Th). ${ }^{164}$ Th cells activate antigen-specific effector cells and recruit the innate immune system such as macrophages, eosinophil granulocytes, and mast cells. Tumor antigen-specific Th cells are activated by either antigen-presenting cells or directly by major histocompatibility complex (MHC) class II expressing tumors. Many vaccine strategies aim to stimulate the Th response specific for a tumor antigen. Immune functions show circadian variations: circulating antibodies, total lymphocytes, and cell-mediated immune responses. ${ }^{165}$ Circadian rhythm thereby influences the organization of cellular immune function. Levels of T cytotoxic lymphocytes, natural killer cells, and $\gamma \delta \mathrm{TCR}$-bearing cells in peripheral blood, show the lowest levels at night and rise to a maximum around midday, whereas CD4+ Th cells have higher nocturnal levels. ${ }^{165,166}$ In addition, circadian changes can be observed in the process of cell production, release and action of cytokines and chemokines that influence cell redistribution to the bone marrow, mobilization, and migration to lymphoid and nonlymphoid organs. Different lymphocytes populations, the level of IL-2, melatonin, and cortisol were compared in normal healthy controls with non-small lung cancer patients. In healthy controls, circadian rhythm was observed in CD8+, CD16+, $\gamma \delta$ TCR cells, and cortisol levels peaking at daytime, and in CD3+, CD4+, CD20+ cells, and melatonin levels peaking at nighttime. In non-small lung cancer patients, circadian rhythm was observed in CD16+, $\gamma \delta$ TCR cells, and cortisol levels peaking at daytime, and CD4+, CD25+ cells, and melatonin levels peaking at nighttime. Although levels differ, the similarity in peak times for some lymphocyte subsets and hormones suggests that timed circadian administration of immunotherapy may improve the efficacy of treatment. ${ }^{165}$ As evidence for this, it was shown that CD4+ T cell responses are regulated by a cellular circadian oscillator capable of driving rhythmic CD4+ T cell immune responses. ${ }^{167}$

Each person has his or her own circadian rhythm, and unlike studies performed on rodents with identical genetic background, these interindividual differences in humans should be taken into account when chronotherapies are modeled and designed. Depending on our everyday routine, we are ranked into different chronotypes that are dependent on age, sex, geographical location, and genotype. ${ }^{168}$ To obtain informative data that are feasible in clinical settings, different noninvasive approaches are considered. One such measurement is actimetry, which is based on rest-activity pattern monitoring of the individual. To get reliable data, recording over several days (eg, 1 week) and the use of a wristwatch accelerometer are recommended. ${ }^{169}$ Rest-activity pattern can differ largely among cancer patients. ${ }^{170,171}$ Circadian rhythm disruption is a robust predictor of long-term survival outcomes in metastatic colorectal patients. ${ }^{170}$ It was shown that chemotherapy could disrupt a patient's circadian rhythm, which is also a poor predictor of survival. ${ }^{160}$ Another possible measurement of circadian rhythm is body temperature. The core body temperature can be measured with the use of rectal probes where high values usually occur in the late afternoon and the nadir is reached at late night. ${ }^{172}$ This system is not particularly comfortable for cancer patients. The temperature can also be measured at skin surface: the highest measurement is usually recorded at early night, and the lowest in the early morning. ${ }^{173}$ The measurement of skin surface temperature, the rest-activity pattern, and position recording was called TAP (Temperature-ActivityPosition). TAP displayed stable measurement of individual rhythm compared with individual measurement and could be best served as a readout of cancer patient chronotype measurement. ${ }^{174}$

Patterns of hormones cortisol and melatonin vary during the day and can be measured noninvasively: in saliva 
(cortisol and melatonin) and in urine (melatonin). Melatonin secretion usually peaks at early night and is strongly inhibited by night light in humans, ${ }^{175}$ while cortisol secretion peaks around the waking hours, with lowest levels at early night. ${ }^{176}$ The combination of these two can represent a new readout of the patient's chronotype. Salivary cortisol patterns are prognostic factors for the survival of metastatic breast cancer patients, ${ }^{177,178}$ ovarian carcinoma patients, ${ }^{179}$ and lung cancer patients. ${ }^{180}$ No such relation was found for metastatic colorectal patients. ${ }^{181}$

\section{Conclusion}

Experimental and clinical reports show that a robust circadian system is relevant for host control of cancer progression and treatment tolerability, that its disruption accelerates cancer progression, and that it is an independent prognostic factor for the survival of patients with different cancers. ${ }^{170,178,182}$ Chronobiotics such as bright light, physical and social activity, meal timing, and sleep patterns could further strengthen or resynchronize the circadian timing system ${ }^{183,184}$ and help to improve anticancer therapy outcome.

\section{Acknowledgments}

U Prosenc Zmrzljak is supported by the Slovenian Research Agency (ARRS) program P1-0104. I thank Rok Košir for the thoughtful reading of the manuscript and for useful comments.

\section{Disclosure}

The author reports no conflicts of interest in this work.

\section{References}

1. Foster RG, Hankins MW, Peirson SN. Light, photoreceptors, and circadian clocks. In: Rosato E, editor. Circadian Rhythms. Totowa, NJ: Humana Press; 2007. Methods in Molecular Biology ${ }^{\mathrm{TM}}$, 362:3-28.

2. Sancar A. Regulation of the mammalian circadian clock by cryptochrome. J Biol Chem. 2004;279(33):34079-34082.

3. Okamura H. Suprachiasmatic nucleus clock time in the mammalian circadian system. Cold Spring Harb Symp Quant Biol. 2007;72: 551-556.

4. Weaver DR. The suprachiasmatic nucleus: a 25 -year retrospective. J Biol Rhythms. 1998;13(2):100-112.

5. King DP, Zhao Y, Sangoram AM, et al. Positional cloning of the mouse circadian clock gene. Cell. 1997;89(4):641-653.

6. Vitaterna MH, King DP, Chang AM, et al. Mutagenesis and mapping of a mouse gene, Clock, essential for circadian behavior. Science. 1994;264(5159):719-725.

7. Bunger MK, Wilsbacher LD, Moran SM, et al. Mop3 is an essential component of the master circadian pacemaker in mammals. Cell. 2000;103(7):1009-1017.

8. Sangoram AM, Saez L, Antoch MP, et al. Mammalian mircadian autoregulatory loop: a timeless ortholog and $\mathrm{mPer} 1$ interact and negatively regulate CLOCK-BMAL1-induced transcription. Neuron. 1998;21(5): $1101-1113$.
9. Lee C, Etchegaray J-P, Cagampang FRA, Loudon ASI, Reppert SM Posttranslational mechanisms regulate the mammalian circadian clock. Cell. 2001;107(7):855-867.

10. Shearman LP, Jin X, Lee C, Reppert SM, Weaver DR. Targeted disruption of the mPer3 gene: subtle effects on circadian clock function. Mol Cell Biol. 2000;20(17):6269-6275.

11. Akashi M, Tsuchiya Y, Yoshino T, Nishida E. Control of intracellular dynamics of mammalian period proteins by casein kinase I $\varepsilon$ (CKIE) and CKI $\delta$ in cultured cells. Mol Cell Biol. 2002;22(6): 1693-1703.

12. Xu Y, Padiath QS, Shapiro RE, et al. Functional consequences of a CKI $\delta$ mutation causing familial advanced sleep phase syndrome. Nature. 2005;434(7033):640-644.

13. Bieler J, Cannavo R, Gustafson K, Gobet C, Gatfield D, Naef F. Robust synchronization of coupled circadian and cell cycle oscillators in single mammalian cells. Mol Syst Biol. 2014;10(7):739.

14. Hahn AT, Jones JT, Meyer T. Quantitative analysis of cell cycle phase durations and $\mathrm{PC} 12$ differentiation using fluorescent biosensors. Cell Cycle. 2009;8(7):1044-1052.

15. Mori T, Binder B, Johnson CH. Circadian gating of cell division in cyanobacteria growing with average doubling times of less than 24 hours. Proc Natl Acad Sci. 1996;93(19):10183-10188.

16. Hong CI, Zámborszky J, Baek M, et al. Circadian rhythms synchronize mitosis in Neurospora crassa. Proc Natl Acad Sci. 2014;111(4): 1397-1402.

17. Tamai TK, Young LC, Cox CA, Whitmore D. Light acts on the zebrafish circadian clock to suppress rhythmic mitosis and cell proliferation. J Biol Rhythms. 2012;27(3):226-236.

18. Brown WR. A review and mathematical analysis of circadian rhythms in cell proliferation in mouse, rat, and human epidermis. J Invest Dermatol. 1991;97(2):273-280.

19. Kowalska E, Ripperger JA, Hoegger DC, et al. NONO couples the circadian clock to the cell cycle. Proc Natl Acad Sci. 2013;110(5): 1592-1599.

20. Bjarnason GA, Jordan RCK, Wood PA, et al. Circadian expression of clock genes in human oral mucosa and skin: association with specific cell-cycle phases. Am J Pathol. 2001;158(5):1793-1801.

21. Masri S, Cervantes M, Sassone-Corsi P. The circadian clock and cell cycle: interconnected biological circuits. Curr Opin Cell Biol. 2013;25(6):730-734.

22. Matsuo T, Yamaguchi S, Mitsui S, Emi A, Shimoda F, Okamura H. Control mechanism of the circadian clock for timing of cell division in vivo. Science 2003;302(5643):255-259.

23. Galluzzi L, Maiuri MC, Vitale I, et al. Cell death modalities: classification and pathophysiological implications. Cell Death Differ. 2007;14(7):1237-1243.

24. Mansilla S, Bataller M, Portugal J. Mitotic catastrophe as a consequence of chemotherapy. Anticancer Agents Med Chem. 2006;6(6): 589-602.

25. Hoogerwerf WA. Biologic clocks and the gut. Curr Gastroenterol Rep. 2006;8(5):353-359.

26. Geyfman M, Andersen B. Clock genes, hair growth and aging. Aging. 2010;2(3):122-128.

27. Smith J, Tho LM, Xu N, Gillespie DA. The ATM-Chk2 and ATR-Chk1 pathways in DNA damage signaling and cancer. Adv Cancer Res. 2010;108:73-112.

28. Gery S, Komatsu N, Baldjyan L, Yu A, Koo D, Koeffler HP. The circadian gene Per1 plays an important role in cell growth and DNA damage control in human cancer cells. Mol Cell. 2006;22(3):375-382.

29. Barnes JW, Tischkau SA, Barnes JA, et al. Requirement of mammalian timeless for circadian rhythmicity. Science. 2003;302(5644):439-442.

30. Ünsal-Kaçmaz K, Mullen TE, Kaufmann WK, Sancar A. Coupling of human circadian and cell cycles by the timeless protein. Mol Cell Biol. 2005;25(8):3109-3116.

31. Kanai S, Kikuno R, Toh H, Ryo H, Todo T. Molecular evolution of the photolyase-blue-light photoreceptor family. J Mol Evol. 1997;45(5): $535-548$. 
32. Chaves I, Nijman RM, Biernat MA, et al. The Potorous CPD photolyase rescues a cryptochrome-deficient mammalian circadian clock. PLoS One. 2011;6(8):e23447.

33. Kang T-H, Reardon JT, Kemp M, Sancar A. Circadian oscillation of nucleotide excision repair in mammalian brain. Proc Natl Acad Sci. 2009;106(8):2864-2867.

34. Kang T-H, Lindsey-Boltz LA, Reardon JT, Sancar A. Circadian control of XPA and excision repair of cisplatin-DNA damage by cryptochrome and HERC2 ubiquitin ligase. Proc Natl Acad Sci. 2010;107(11):4890-4895.

35. Gaddameedhi S, Selby CP, Kaufmann WK, Smart RC, Sancar A. Control of skin cancer by the circadian rhythm. Proc Natl Acad Sci. 2011;108(46):18790-18795.

36. Cotta-Ramusino C, McDonald ER, Hurov K, Sowa ME, Harper JW, Elledge SJ. A DNA damage response screen identifies RHINO, a 9-1-1 and TopBP1 interacting protein required for ATR signaling. Science. 2011;332(6035):1313-1317.

37. Kang T-H, Sancar A. Circadian regulation of DNA excision repair: implications for chrono-chemotherapy. Cell Cycle. 2009;8(11): $1665-1667$.

38. Antoch MP, Kondratov RV. Pharmacological modulators of the circadian clock as potential therapeutic drugs: focus on genotoxic/anticancer therapy. In: Kramer A, Merrow M, editors. Circadian Clocks. Berlin: Springer; 2013. Handbook of Experimental Pharmacology, 217:289-309.

39. Lévi F, Okyar A, Dulong S, Innominato PF, Clairambault J. Circadian timing in cancer treatments. Annu Rev Pharmacol Toxicol. 2010;50(1):377-421.

40. Mazzoccoli G, Panza A, Valvano MR, et al. Clock gene expression levels and relationship with clinical and pathological features in colorectal cancer patients. Chronobiol Int. 2011;28(10):841-851.

41. Wang Y, Hua L, Lu C, Chen Z. Expression of circadian clock gene human Period2 (hPer2) in human colorectal carcinoma. World J Surg Oncol. 2011;9(1):166.

42. Eisele L, Prinz R, Klein-Hitpass L, et al. Combined PER2 and CRY1 expression predicts outcome in chronic lymphocytic leukemia. Eur $J$ Haematol. 2009;83(4):320-327.

43. Tokunaga $\mathrm{H}$, Takebayashi $\mathrm{Y}$, Utsunomiya $\mathrm{H}$, et al. Clinicopathological significance of circadian rhythm-related gene expression levels in patients with epithelial ovarian cancer. Acta Obstet Gynecol Scand. 2008;87(10):1060-1070.

44. Yi C, Mu L, de la Longrais IAR, et al. The circadian gene NPAS2 is a novel prognostic biomarker for breast cancer. Breast Cancer Res Treat. 2010;120(3):663-669.

45. Chu LW, Zhu Y, Yu K, et al. Variants in circadian genes and prostate cancer risk: a population-based study in China. Prostate Cancer Prostatic Dis. 2007;11(4):342-348.

46. Zhu Y, Stevens RG, Leaderer D, et al. Non-synonymous polymorphisms in the circadian gene NPAS2 and breast cancer risk. Breast Cancer Res Treat. 2008;107(3):421-425.

47. Hoffman AE, Zheng T, Stevens RG, et al. Clock-cancer connection in non-Hodgkin's lymphoma: a genetic association study and pathway analysis of the circadian gene cryptochrome 2. Cancer Res. 2009;69(8):3605-3613

48. Karantanos T, Theodoropoulos G, Gazouli M, et al. Association of the clock genes polymorphisms with colorectal cancer susceptibility. J Surg Oncol. 2013;108(8):563-567.

49. Chen S-T, Choo K-B, Hou M-F, Yeh K-T, Kuo S-J, Chang J-G. Deregulated expression of the PER1, PER2 and PER3 genes in breast cancers. Carcinogenesis. 2005;26(7):1241-1246.

50. Gery S, Gombart AF, Yi WS, Koeffler C, Hofmann W-K, Koeffler HP. Transcription profiling of C/EBP targets identifies Per2 as a gene implicated in myeloid leukemia. Blood. 2005;106(8):2827-2836.

51. Gery S, Virk RK, Chumakov K, Yu A, Koeffler HP. The clock gene Per2 links the circadian system to the estrogen receptor. Oncogene. 2007;26(57):7916-7920.
52. Guess J, Burch JB, Ogoussan K, et al. Circadian disruption, Per3, and human cytokine secretion. Integr Cancer Ther. 2009;8(4): 329-336.

53. Fu L, Pelicano H, Liu J, Huang P, Lee CC. The circadian gene Period2 plays an important role in tumor suppression and DNA damage response in vivo. Cell. 2002;111(1):41-50.

54. Wood PA, Yang X, Taber A, et al. Period 2 mutation accelerates ApcMin/+ tumorigenesis. Mol Cancer Res. 2008;6(11):1786-1793.

55. Yang X, Wood PA, Ansell CM, et al. Beta-catenin induces beta-TrCPmediated PER2 degradation altering circadian clock gene expression in intestinal mucosa of ApcMin/+ mice. J Biochem (Tokyo). 2009;145(3): 289-297.

56. Yang X, Wood PA, Oh E-Y, Du-Quiton J, Ansell CM, Hrushesky WJM. Down regulation of circadian clock gene Period 2 accelerates breast cancer growth by altering its daily growth rhythm. Breast Cancer Res Treat. 2009;117(2):423-431.

57. Hua $\mathrm{H}$, Wang $\mathrm{Y}$, Wan $\mathrm{C}$, et al. Inhibition of tumorigenesis by intratumoral delivery of the circadian gene mPer2 in C57BL/6 mice. Cancer Gene Ther. 2007;14(9):815-818.

58. Yang X, Wood PA, Ansell CM, et al. The circadian clock gene Per1 suppresses cancer cell proliferation and tumor growth at specific times of day. Chronobiol Int. 2009;26(7):1323-1339.

59. Lee H-J, Kim L, Kang S-G, et al. PER2 variation is associated with diurnal preference in a Korean Young Population. Behav Genet. 2011;41(2):273-277.

60. Zhu Y, Brown HN, Zhang Y, Stevens RG, Zheng T. Period3 structural variation: a circadian biomarker associated with breast cancer in young women. Cancer Epidemiol Biomarkers Prev. 2005;14(1): $268-270$.

61. Soták M, Polidarová L, Ergang P, Sumová A, Pácha J. An association between clock genes and clock-controlled cell cycle genes in murine colorectal tumors. Int J Cancer. 2013;132(5):1032-1041.

62. Sahar S, Zocchi L, Kinoshita C, Borrelli E, Sassone-Corsi P. Regulation of BMAL1 protein stability and circadian function by GSK3 $\beta$-mediated phosphorylation. PLoS One. 2010;5(1):e8561.

63. Chen J, Huang X-F. The signal pathways in azoxymethane-induced colon cancer and preventive implications. Cancer Biol Ther. 2009;8(14): 1313-1317.

64. Relógio A, Thomas P, Medina-Pérez P, et al. Ras-mediated deregulation of the circadian clock in cancer. PLoS Genet. 2014;10(5): e1004338.

65. International Agency for Research on Cancer. IARC Monogarphs Painting, Firefighting and Shift Work. Lyon France: International Agency for Research on Cancer; 2010.

66. Jenuwein T, Allis CD. Translating the histone code. Science. 2001; 293(5532):1074-1080.

67. Crosio C, Cermakian N, Allis CD, Sassone-Corsi P. Light induces chromatin modification in cells of the mammalian circadian clock. Nat Neurosci. 2000;3(12):1241-1247.

68. Ripperger JA, Schibler U. Rhythmic CLOCK-BMAL1 binding to multiple E-box motifs drives circadian Dbp transcription and chromatin transitions. Nat Genet. 2006;38(3):369-374.

69. Etchegaray J-P, Lee C, Wade PA, Reppert SM. Rhythmic histone acetylation underlies transcription in the mammalian circadian clock. Nature. 2003;421(6919):177-182.

70. Doi M, Hirayama J, Sassone-Corsi P. Circadian regulator CLOCK is a histone acetyltransferase. Cell. 2006;125(3):497-508.

71. Hirayama J, Sahar S, Grimaldi B, et al. CLOCK-mediated acetylation of BMAL1 controls circadian function. Nature. 2007;450(7172): 1086-1090.

72. Katada S, Sassone-Corsi P. The histone methyltransferase MLL1 permits the oscillation of circadian gene expression. Nat Struct Mol Biol. 2010;17(12):1414-1421.

73. Asher G, Gatfield D, Stratmann M, et al. SIRT1 regulates circadian clock gene expression through PER2 deacetylation. Cell. 2008;134(2): 317-328. 
74. Bishop NA, Guarente L. Genetic links between diet and lifespan: shared mechanisms from yeast to humans. Nat Rev Genet. 2007;8(11): 835-844.

75. Nakahata Y, Sahar S, Astarita G, Kaluzova M, Sassone-Corsi P. Circadian control of the NAD+ salvage pathway by CLOCK-SIRT1. Science. 2009;324(5927):654-657.

76. Schwer B, Verdin E. Conserved metabolic regulatory functions of sirtuins. Cell Metab. 2008;7(2):104-112.

77. Feng D, Liu T, Sun Z, et al. A circadian rhythm orchestrated by histone deacetylase 3 controls hepatic lipid metabolism. Science. 2011;331(6022):1315-1319.

78. Duong HA, Robles MS, Knutti D, Weitz CJ. A molecular mechanism for circadian clock negative feedback. Science. 2011;332(6036): 1436-1439.

79. Shaknovich R, De S, Michor F. Epigenetic diversity in hematopoietic neoplasms. Biochim Biophys Acta BBA-Rev Cancer. 2014;1846(2): $477-484$.

80. Nakamura J. Methylation-mediated gene silencing as biomarkers of gastric cancer: a review. World J Gastroenterol. 2014;20(34):11991.

81. Mikeska T, Craig JM. DNA methylation biomarkers: cancer and beyond. Genes. 2014;5(3):821-864.

82. Newton K, Jorgensen NM, Wallace AJ, et al. Tumour MLH1 promoter region methylation testing is an effective prescreen for Lynch Syndrome (HNPCC). J Med Genet. Epub October 13, 2014.

83. Wentzensen N, Sherman ME, Schiffman M, Wang SS. Utility of methylation markers in cervical cancer early detection: appraisal of the state-of-the-science. Gynecol Oncol. 2009;112(2):293-299.

84. Kino T, Chrousos GP. Acetylation-mediated epigenetic regulation of glucocorticoid receptor activity: circadian rhythm-associated alterations of glucocorticoid actions in target tissues. Mol Cell Endocrinol. 2011;336(1-2):23-30.

85. Chrousos GP. The hypothalamic-pituitary-adrenal axis and immunemediated inflammation. $N$ Engl J Med. 1995;332(20):1351-1363.

86. Ito K, Yamamura S, Essilfie-Quaye S, et al. Histone deacetylase 2-mediated deacetylation of the glucocorticoid receptor enables NF- $\kappa \mathrm{B}$ suppression. J Exp Med. 2006;203(1):7-13.

87. Nader N, Chrousos GP, Kino T. Circadian rhythm transcription factor CLOCK regulates the transcriptional activity of the glucocorticoid receptor by acetylating its hinge region lysine cluster: potential physiological implications. FASEB J. 2009;23(5):1572-1583.

88. Nader N, Chrousos GP, Kino T. Interactions of the circadian CLOCK system and the HPA axis. Trends Endocrinol Metab. 2010; 21(5):277-286.

89. Dunn GP, Old LJ, Schreiber RD. The immunobiology of cancer immunosurveillance and immunoediting. Immunity. 2004;21(2):137-148.

90. Li D, Bi F-F, Chen N-N, et al. A novel crosstalk between BRCA1 and sirtuin 1 in ovarian cancer. Sci Rep. 2014;4:6666.

91. Teboul M, Guillaumond F, Gréchez-Cassiau A, Delaunay F. Minireview: the nuclear hormone receptor family round the clock. Mol Endocrinol. 2008;22(12):2573-2582.

92. Coumoul X, Diry M, Barouki R. PXR-dependent induction of human CYP3A4 gene expression by organochlorine pesticides. Biochem Pharmacol. 2002;64(10):1513-1519.

93. Ourlin JC, Lasserre F, Pineau T, et al. The small heterodimer partner interacts with the pregnane $\mathrm{X}$ receptor and represses its transcriptional activity. Mol Endocrinol. 2003;17(9):1693-1703.

94. Oiwa A, Kakizawa T, Miyamoto T, et al. Synergistic regulation of the mouse orphan nuclear receptor SHP gene promoter by CLOCKBMAL1 and LRH-1. Biochem Biophys Res Commun. 2007;353(4): 895-901.

95. Dioum EM, Rutter J, Tuckerman JR, Gonzalez G, Gilles-Gonzalez M-A, McKnight SL. NPAS2: a gas-responsive transcription factor. Science. 2002;298(5602):2385-2387.

96. Claudel T, Cretenet G, Saumet A, Gachon F. Crosstalk between xenobiotics metabolism and circadian clock. FEBS Lett. 2007;581(19): 3626-3633.
97. Zhang Y-KJ, Yeager RL, Klaassen CD. Circadian expression profiles of drug-processing genes and transcription factors in mouse liver. Drug Metab Dispos. 2009;37(1):106-115.

98. Takiguchi T, Tomita M, Matsunaga N, Nakagawa H, Koyanagi S, Ohdo S. Molecular basis for rhythmic expression of CYP3A4 in serum-shocked HepG2 cells. Pharmacogenet Genomics. 2007;17(12): 1047-1056

99. Zmrzljak UP, Rozman D. Circadian regulation of the hepatic endobiotic and xenobitoic detoxification pathways: the time matters. Chem Res Toxicol. 2012;25(4):811-824.

100. Zuber AM, Centeno G, Pradervand S, et al. Molecular clock is involved in predictive circadian adjustment of renal function. Proc Natl Acad Sci. 2009;106(38):16523-16528.

101. Gachon F, Olela FF, Schaad O, Descombes P, Schibler U. The circadian PAR-domain basic leucine zipper transcription factors DBP, TEF, and HLF modulate basal and inducible xenobiotic detoxification. Cell Metab. 2006;4(1):25-36.

102. Gorbacheva VY, Kondratov RV, Zhang R, et al. Circadian sensitivity to the chemotherapeutic agent cyclophosphamide depends on the functional status of the CLOCK/BMAL1 transactivation complex. Proc Natl Acad Sci U S A. 2005;102(9):3407-3412.

103. Storch K-F, Lipan O, Leykin I, et al. Extensive and divergent circadian gene expression in liver and heart. Nature. 2002;417(6884):78-83.

104. Levi F, Schibler U. Circadian rhythms: mechanisms and therapeutic implications. Annu Rev Pharmacol Toxicol. 2007;47:593-628.

105. Li X-M, Metzger G, Filipski E, et al. Pharmacologic modulation of reduced glutathione circadian rhythms with buthionine sulfoximine: relationship with cisplatin toxicity in mice. Toxicol Appl Pharmacol. 1997;143(2):281-290.

106. Li XM, Metzger G, Filipski E, Lemaigre G, Lévi F. Modulation of nonprotein sulphydryl compounds rhythm with buthionine sulphoximine: relationship with oxaliplatin toxicity in mice. Arch Toxicol. 1998;72(9):574-579.

107. Labrecque G, Bélanger PM. Basic mechanisms of chronopharmacology [In French]. Pathol Biol (Paris). 1987;35(6):917-923.

108. Boughattas NA, Lévi F, Fournier C, et al. Circadian rhythm in toxicities and tissue uptake of 1,2-diamminocyclohexane(trans-1) oxalatoplatinum(II) in mice. Cancer Res. 1989;49(12):3362-3368.

109. Balsalobre A, Damiola F, Schibler U. A serum shock induces circadian gene expression in mammalian tissue culture cells. Cell. 1998;93(6): 929-937.

110. Balsalobre A, Brown SA, Marcacci L, et al. Resetting of circadian time in peripheral tissues by glucocorticoid signaling. Science. 2000;289(5488):2344-2347.

111. Yagita K, Okamura H. Forskolin induces circadian gene expression of rPer1, rPer2 and dbp in mammalian rat-1 fibroblasts. FEBS Lett. 2000;465(1):79-82.

112. Balsalobre A, Marcacci L, Schibler U. Multiple signaling pathways elicit circadian gene expression in cultured Rat-1 fibroblasts. Curr Biol. 2000;10(20):1291-1294.

113. Yagita K, Tamanini F, van der Horst GTJ, Okamura H. Molecular mechanisms of the biological clock in cultured fibroblasts. Science. 2001;292(5515):278-281.

114. Hirota T, Okano T, Kokame K, Shirotani-Ikejima H, Miyata T, Fukada Y. Glucose down-regulates Per1 and Per2mRNA levels and induces circadian gene expression in cultured rat-1 fibroblasts. $J$ Biol Chem. 2002;277(46):44244-44251.

115. Tsuchiya Y, Minami I, Kadotani H, Nishida E. Resetting of peripheral circadian clock by prostaglandin E2. EMBO Rep. 2005;6(3) 256-261.

116. Ramsey KM, Yoshino J, Brace CS, et al. Circadian clock feedback cycle through NAMPT-mediated NAD+ biosynthesis. Science. 2009;324(5927):651-654.

117. Raghuram S, Stayrook KR, Huang P, et al. Identification of heme as the ligand for the orphan nuclear receptors REV-ERB $\alpha$ and REV-ERB $\beta$. Nat Struct Mol Biol. 2007;14(12):1207-1213. 
118. O'Neill JS, Maywood ES, Chesham JE, Takahashi JS, Hastings MH. cAMP-dependent signaling as a core component of the mammalian circadian pacemaker. Science. 2008;320(5878):949-953.

119. Izumo M, Sato TR, Straume M, Johnson CH. Quantitative analyses of circadian gene expression in mammalian cell cultures. PLoS Comput Biol. 2006;2(10):e136.

120. Hirota T, Lewis WG, Liu AC, Lee JW, Schultz PG, Kay SA. A chemical biology approach reveals period shortening of the mammalian circadian clock by specific inhibition of GSK-3ß. Proc Natl Acad Sci. 2008;105(52):20746-20751.

121. Harada Y, Sakai M, Kurabayashi N, Hirota T, Fukada Y. Ser-557-phosphorylated mCRY2 is degraded upon synergistic

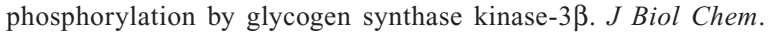
2005;280(36):31714-31721.

122. Iitaka C, Miyazaki K, Akaike T, Ishida N. A Role for glycogen synthase kinase- $3 \beta$ in the mammalian circadian clock. J Biol Chem. 2005;280(33):29397-29402.

123. Spengler ML, Kuropatwinski KK, Schumer M, Antoch M. A serine cluster mediates BMAL1-dependent CLOCK phosphorylation and degradation. Cell Cycle. 2009;8(24):4138-4146.

124. Yin L, Wang J, Klein PS, Lazar MA. Nuclear receptor Rev-erb $\alpha$ is a critical lithium-sensitive component of the circadian clock. Science. 2006;311(5763):1002-1005.

125. Hirota T, Lee JW, Lewis WG, et al. High-throughput chemical screen identifies a novel potent modulator of cellular circadian rhythms and reveals CKI $\alpha$ as a clock regulatory kinase. PLoS Biol. 2010;8(12): e1000559.

126. Chen Z, Yoo S-H, Park Y-S, et al. Identification of diverse modulators of central and peripheral circadian clocks by high-throughput chemical screening. Proc Natl Acad Sci. 2012;109(1):101-106.

127. Hirota T, Lee JW, John PCS, et al. Identification of small molecule activators of cryptochrome. Science. 2012;337(6098):1094-1097.

128. Lamia KA, Papp SJ, Yu RT, et al. Cryptochromes mediate rhythmic repression of the glucocorticoid receptor. Nature. 2011;480(7378): $552-556$.

129. Zhang EE, Liu Y, Dentin R, et al. Cryptochrome mediates circadian regulation of cAMP signaling and hepatic gluconeogenesis. Nat Med. 2010;16(10):1152-1156.

130. Yu EA, Weaver DR. Disrupting the circadian clock: gene-specific effects on aging, cancer, and other phenotypes. Aging. 2011;3(5): 479-493.

131. HuY, Spengler ML, Kuropatwinski KK, et al. Selenium is a modulator of circadian clock that protects mice from the toxicity of a chemotherapeutic drug via upregulation of the core clock protein, BMAL1. Oncotarget. 2011;2(12):1279-1290.

132. Antoch MP, Chernov MV. Pharmacological modulators of the circadian clock as potential therapeutic drugs. Mutat Res. 2009;680(1-2): 109-115.

133. Gehrisch A, Dörr PDW. Effects of systemic or topical administration of sodium selenite on early radiation effects in mouse oral mucosa. Strahlenther Onkol. 2007;183(1):36-42.

134. Muecke R, Schomburg L, Glatzel M, et al. Multicenter, phase 3 trial comparing selenium supplementation with observation in gynecologic radiation oncology. Int J Radiat Oncol. 2010;78(3):828-835.

135. Ozturk N, Lee JH, Gaddameedhi S, Sancar A. Loss of cryptochrome reduces cancer risk in p53 mutant mice. Proc Natl Acad Sci. 2009;106(8):2841-2846.

136. Yu J, Baron V, Mercola D, Mustelin T, Adamson ED. A network of p73, p53 and Egr1 is required for efficient apoptosis in tumor cells. Cell Death Differ. 2006;14(3):436-446.

137. Lee JH, Sancar A. Circadian clock disruption improves the efficacy of chemotherapy through p73-mediated apoptosis. Proc Natl Acad Sci. 2011;108(26):10668-10672.

138. Lévi F, Okyar A. Circadian clocks and drug delivery systems: impact and opportunities in chronotherapeutics. Expert Opin Drug Deliv. 2011;8(12):1535-1541.
139. Lévi F, Misset JL, Brienza S, et al. A chronopharmacologic phase II clinical trial with 5-fluorouracil, folinic acid, and oxaliplatin using an ambulatory multichannel programmable pump. High antitumor effectiveness against metastatic colorectal cancer. Cancer. 1992;69(4): 893-900.

140. Vassal G, Challine D, Koscielny S, et al. Chronopharmacology of high-dose busulfan in children. Cancer Res. 1993;53(7):1534-1537.

141. Rivard GE, Infante-Rivard C, Dresse MF, Leclerc JM, Champagne J. Circadian time-dependent response of childhood lymphoblastic leukemia to chemotherapy: a long-term follow-up study of survival. Chronobiol Int. 1993;10(3):201-204.

142. Etienne-Grimaldi M-C, Cardot J-M, François E, et al. Chronopharmacokinetics of oral tegafur and uracil in colorectal cancer patients. Clin Pharmacol Ther. 2007;83(3):413-415.

143. Spies CM, Cutolo M, Straub RH, Burmester GR, Buttgereit F. Prednisone chronotherapy. Clin Exp Rheumatol. 2011;29(5 Suppl 68): S42-S45.

144. Sothern RB, Lévi F, Haus E, Halberg F, Hrushesky WJ. Control of a murine plasmacytoma with doxorubicin-cisplatin: dependence on circadian stage of treatment. J Natl Cancer Inst. 1989;81(2):135-145.

145. Granda TG, D'Attino R-M, Filipski E, et al. Circadian optimisation of irinotecan and oxaliplatin efficacy in mice with Glasgow osteosarcoma. Br J Cancer. 2002;86(6):999-1005.

146. Li XM, Tanaka K, Sun J, et al. Preclinical relevance of dosing time for the therapeutic index of gemcitabine-cisplatin. $\mathrm{Br} J$ Cancer. 2005;92(9):1684-1689.

147. Granda TG, Filipski E, D'Attino RM, et al. Experimental chronotherapy of mouse mammary adenocarcinoma MA13/C with docetaxel and doxorubicin as single agents and in combination. Cancer Res. 2001;61(5):1996-2001.

148. Focan C, Denis B, Kreutz F, Focan-Henrard D, Levi F. Ambulatory chronotherapy with 5-fluorouracil, folinic acid, and carboplatin for advanced non-small cell lung cancer. A phase II feasibility trial. J Infus Chemother. 1995;5(3 Suppl 1):148-152.

149. Hrushesky WJ. Circadian timing of cancer chemotherapy. Science. 1985;228(4695):73-75.

150. Lévi F, Benavides M, Chevelle C, et al. Chemotherapy of advanced ovarian cancer with $4^{\prime}$-O-tetrahydropyranyl doxorubicin and cisplatin: a randomized phase II trial with an evaluation of circadian timing and dose-intensity. J Clin Oncol Off J Am Soc Clin Oncol. 1990;8(4): 705-714.

151. Caussanel JP, Lévi F, Brienza S, et al. Phase I trial of 5-day continuous venous infusion of oxaliplatin at circadian rhythm-modulated rate compared with constant rate. J Natl Cancer Inst. 1990;82(12): 1046-1050.

152. Levi F, Perpoint B, Garufi C, et al. Oxaliplatin activity against metastatic colorectal cancer. A phase II study of 5-day continuous venous infusion at circadian rhythm modulated rate. Eur $J$ Cancer. 1993;29A(9):1280-1284.

153. Lévi FA, Zidani R, Vannetzel JM, et al. Chronomodulated versus fixedinfusion-rate delivery of ambulatory chemotherapy with oxaliplatin, fluorouracil, and folinic acid (leucovorin) in patients with colorectal cancer metastases: a randomized multi-institutional trial. J Natl Cancer Inst. 1994;86(21):1608-1617.

154. Lévi F, Zidani R, Misset J-L. Randomised multicentre trial of chronotherapy with oxaliplatin, fluorouracil, and folinic acid in metastatic colorectal cancer. Lancet. 1997;350(9079):681-686.

155. Giacchetti S, Bjarnason G, Garufi C, et al. Phase III trial comparing 4-day chronomodulated therapy versus 2-day conventional delivery of fluorouracil, leucovorin, and oxaliplatin as first-line chemotherapy of metastatic colorectal cancer: The European Organisation for Research and Treatment of Cancer Chronotherapy Group. J Clin Oncol. 2006;24(22):3562-3569.

156. Ahowesso C, Piccolo E, Li XM, et al. Relations between strain and gender dependencies of irinotecan toxicity and UGT1A1, CES2 and TOP1 expressions in mice. Toxicol Lett. 2010;192(3):395-401. 
157. Okyar A, Piccolo E, Ahowesso C, et al. Strain- and sex-dependent circadian changes in Abcc 2 transporter expression: implications for irinotecan chronotolerance in mouse ileum. PLoS One. 2011;6(6): e20393.

158. Jeffrey Wang BSP, Ying Huang BSP. Pharmacogenomics of sex difference in chemotherapeutic toxicity. Curr Drug Discov Technol. 2007;4(1):59-68.

159. Bur IM, Cohen-Solal AM, Carmignac D, et al. The circadian clock components CRY1 and CRY2 are necessary to sustain sex dimorphism in mouse liver metabolism. J Biol Chem. 2009;284(14):9066-9073.

160. Innominato PF, Giacchetti S, Moreau T, et al. Prediction of survival by neutropenia according to delivery schedule of oxaliplatin-5-fluorouracilleucovorin for metastatic colorectal cancer in a randomized international trial (EORTC 05963). Chronobiol Int. 2011;28(7):586-600.

161. Bouchahda M, Adam R, Giacchetti S, et al. Rescue chemotherapy using multidrug chronomodulated hepatic arterial infusion for patients with heavily pretreated metastatic colorectal cancer. Cancer. 2009;115(21):4990-4999.

162. Bjarnason GA, MacKenzie RG, Nabid A, et al. Comparison of toxicity associated with early morning versus late afternoon radiotherapy in patients with head-and-neck cancer: a prospective randomized trial of the National Cancer Institute of Canada Clinical Trials Group (HN3). Int J Radiat Oncol. 2009;73(1):166-172.

163. Rahn DA, Ray DK, Schlesinger DJ, et al. Gamma knife radiosurgery for brain metastasis of nonsmall cell lung cancer: is there a difference in outcome between morning and afternoon treatment? Cancer. 2011;117(2):414-420.

164. Knutson KL, Disis ML. Tumor antigen-specific T helper cells in cancer immunity and immunotherapy. Cancer Immunol Immunother. 2005;54(8):721-728.

165. Mazzoccoli G, Sothern RB, Parrella P, et al. Comparison of circadian characteristics for cytotoxic lymphocyte subsets in non-small cell lung cancer patients versus controls. Clin Exp Med. 2012;12(3):181-194.

166. Suzuki S, Toyabe S, Moroda T, et al. Circadian rhythm of leucocytes and lymphocyte subsets and its possible correlation with the function of the autonomic nervous system. Clin Exp Immunol. 1997;110(3): 500-508.

167. Bollinger T, Leutz A, Leliavski A, et al. Circadian clocks in mouse and human CD4+ T cells. PLoS One. 2011;6(12):e29801.

168. Roenneberg T, Kuehnle T, Juda M, et al. Epidemiology of the human circadian clock. Sleep Med Rev. 2007;11(6):429-438.

169. Chevalier V, Mormont M-C, Curé H, Chollet P. Assessment of circadian rhythms by actimetry in healthy subjects and patients with advanced colorectal cancer. Oncol Rep. 2003;10(3):733-737.

170. Mormont M-C, Waterhouse J, Bleuzen P, et al. Marked 24-h rest/ activity rhythms are associated with better quality of life, better response, and longer survival in patients with metastatic colorectal cancer and cood performance status. Clin Cancer Res. 2000;6(8): 3038-3045.
171. Grutsch JF, Wood PA, Du-Quiton J, et al. Validation of actigraphy to assess circadian organization and sleep quality in patients with advanced lung cancer. J Circadian Rhythms. 2011;9:4

172. Waterhouse J, Drust B, Weinert D, et al. The circadian rhythm of core temperature: origin and some implications for exercise performance. Chronobiol Int. 2005;22(2):207-225.

173. Sarabia JA, Rol MA, Mendiola P, Madrid JA. Circadian rhythm of wrist temperature in normal-living subjects: a candidate of new index of the circadian system. Physiol Behav. 2008;95(4):570-580.

174. Ortiz-Tudela E, Martinez-Nicolas A, Campos M, Rol MÁ, Madrid JA. A new integrated variable based on thermometry, actimetry and body position (TAP) to evaluate circadian system status in humans. PLoS Comput Biol. 2010;6(11):e1000996.

175. Hardeland R, Madrid JA, Tan D-X, Reiter RJ. Melatonin, the circadian multioscillator system and health: the need for detailed analyses of peripheral melatonin signaling. J Pineal Res. 2012;52(2): 139-166.

176. Clow A, Hucklebridge F, Thorn L. The cortisol awakening response in context. In: Clow A, Thorn L, editors. Science of Awakening. New York, NY: Academic Press; 2010. International Review of Neurobiology, 93:153-175.

177. Abercrombie HC, Giese-Davis J, Sephton S, Epel ES, Turner-Cobb JM, Spiegel D. Flattened cortisol rhythms in metastatic breast cancer patients. Psychoneuroendocrinology. 2004;29(8):1082-1092.

178. Sephton SE, Sapolsky RM, Kraemer HC, Spiegel D. Diurnal cortisol rhythm as a predictor of breast cancer survival. J Natl Cancer Inst. 2000;92(12):994-1000.

179. Weinrib AZ, Sephton SE, DeGeest K, et al. Diurnal cortisol dysregulation, functional disability, and depression in women with ovarian cancer. Cancer. 2010;116(18):4410-4419.

180. Sephton SE, Lush E, Dedert EA, et al. Diurnal cortisol rhythm as a predictor of lung cancer survival. Brain Behav Immun. 2013;30(Suppl): S163-S170.

181. Mormont M-C, Langouët AM, Claustrat B, et al. Marker rhythms of circadian system function: a study of patients with metastatic colorectal cancer and good performance status. Chronobiol Int. 2002;19(1): 141-155.

182. Innominato PF, Focan C, Gorlia T, et al. Circadian rhythm in rest and activity: a biological correlate of quality of life and a predictor of survival in patients with metastatic colorectal cancer. Cancer Res. 2009;69(11):4700-4707.

183. Ancoli-Israel S, Rissling M, Neikrug A, et al. Light treatment prevents fatigue in women undergoing chemotherapy for breast cancer. Support Care Cancer. 2012;20(6):1211-1219.

184. Seely D, Wu P, Fritz H, et al. Melatonin as adjuvant cancer care with and without chemotherapy a systematic review and meta-analysis of randomized trials. Integr Cancer Ther. 2012;11(4):293-303.
ChronoPhysiology and Therapy

\section{Publish your work in this journal}

ChronoPhysiology and Therapy is an international, peer-reviewed, open access journal focusing on research into the cyclic variations and rhythmicity in physiological processes in the body and the research and development and optimal timing of administration of therapeutic targets to achieve improved outcomes and quality of life for the patient. The

\section{Dovepress}

manuscript management system is completely online and includes a very quick and fair peer-review system. Visit http://www.dovepress.com/ testimonials.php to read real quotes from published authors. 